\title{
Morphometric Discrimination of Females of Five Species of Anopheles of the Subgenus Nyssorhynchus from Southern and Northwest Colombia
}

\author{
David A Calle L, Martha L Quiñones, Holmes F Erazo*, Nicolás Jaramillo O**/+
}

\begin{abstract}
Programa de Estudio y Control de Enfermedades Tropicales **Grupo de Morfometría Biológica, Instituto de Biología, Universidad de Antioquia, A.A. 1226, Medellín, Colombia *Departamento Administrativo de Salud, Putumayo, Colombia
\end{abstract}

The most important vectors of human Plasmodium in the neotropics belong to the subgenus Nyssorhynchus. These species are generally sympatric in terms of their geographical distributions. Some are difficult to identify based solely on examination of adult females using the available morphological keys, in these cases examination of immature stages and male genitalia is required to make correct determinations. However, in epidemiological studies it is necessary to identify the species of adult females which are found near humans, i.e. in studies of malaria transmission or evaluation of control measures. The purpose of the present study was to evaluate the discrimination of adult females of different species of Nyssorhynchus isolated mainly from Southern Colombia (department of Putumayo), using morphometric analysis. Adult females were obtained after rearing larvae collected in natural breeding places and from the progeny of females collected on humans. The morphological characteristics of the immature stages allowed the identification of four species of the subgroup Oswaldoi from Southern Colombia: Anopheles rangeli Gabaldon, Cova Garcia \& Lopez, An. oswaldoi (Peryassu), An. benarrochi Gabaldon, Cova Garcia \& Lopez and An. triannulatus (Neiva \& Pinto). The species An. nuneztovari (Gabaldon) from the Northwest of Colombia was included for comparison. Morphometric analysis allowed differentiation of the females of all species to a confidence level approaching 90\% using principal components analysis of 10 wing and leg variables, followed by canonical variate analysis of the first four principal components. We conclude that morphometrics may represent a useful taxonomic tool for this group and that its use should be further studied.

Key words: taxonomy - traditional morphometrics - malaria - canonical variate analysis - Southern Colombia

The subgenus Nyssorhynchus Blanchard (Diptera: Culicidae) contains the principal vector species of human Plasmodium in the neotropics including Colombia (Faran 1980). Some vectors are generally found to share the same geographical area and present high degree of morphological similarity at the adult stage, particularly among the females. This, together with the fact that the available keys do not take into account the great morphological variability of each species, produces confusion when attempting to identify an isolate based solely on specimens of adult females. For this reason, the characters recommended for accurate species identification are chaetotaxy of the fourth-instar larvae and morphological characters of the male genitalia (Faran 1980).

This problem is well illustrated by the frequent reports of isolation of Anopheles evansae from human bait collections in different areas of Colombia (Quiñones et al. 1987, 1992, Suárez et al. 1990, Perez et al. 1999, Villegas et al. 2000). In this context, Faran (1980) reported that $A n$. evansae is restricted to the Brazilian Amazon, Bolivia and Argentina, suggesting that information on this species in

This research received financial support from the Colciencias (project: 1115-04-460-98) and The Wellcome Trust.

${ }^{+}$Corresponding author. Fax: +57-4-233-0120. E-mail: njaram@epm.net.co

Received 26 March 2002

Accepted 9 October 2002
Colombia may reflect misidentification. In Southern Colombia, by obtaining isofamilies from adult females collected on human bait, it was verified that adult female specimens previously identified as An. evansae were in fact An. benarrochi (Quiñones et al. 2001). The high degree of morphological variability presented by adult females of An. benarrochi in this region also leads to misidentification with An. oswaldoi. In Southern Colombia a morphological variant of $A n$. benarrochi was found in which adult females of this species have the dark portion of the hind tarsomere 2 ranging from 0.17 to 0.33 the length of the tarsomere (Quiñones et al. 2001), which is smaller than described for An. benarrochi in the different available keys (Faran 1980, Faran \& Linthicum 1981, RubioPalis 2000), and overlaps the ranges reported for $A n$. oswaldoi. The presence in Southern Colombia (Putumayo) of An. benarrochi instead of An. evansae was also confirmed by analysis of the nucleotide sequence of ITS-2 region and a fragment of cytochrome oxidase subunit I of mitochondrial DNA (Quiñones et al. 2000). These sequences were particularly useful for separating adult females of An. benarrochi from An. oswaldoi, these being the species whose Putumayo populations are indistinguishable using the available morphological keys.

Traditional multivariate morphometry could contribute towards resolving taxonomic problems such as those mentioned above. Furthermore, this method has been shown to be useful for the distinction of medically important insects that present problems in their identification (Añez et al. 1997, Gebre-Michael \& Medhin 1997, Petrarca 
et al. 1998). Morphometry of Anopheles of the subgenus Nyssorhynchus have been performed in Venezuela producing results that clearly separated different species i.e. An. darlingi, An. marajoara, An. braziliensis and An. argyritarsis, using cluster analysis and Euclidian distances (Rubio-Palis et al. 1997, Rubio-Palis 1998, 2000). In addition, morphometry has been useful in clarifying the taxonomic status of An. darlingi. This species shows considerable variation in biology and morphology along its distribution range suggesting that it could be a species complex. Euclidean distances were estimated by cluster analysis using wing, legs and head characteristics of 17 populations. This information, together with isozyme analysis, RAPD and sequencing of ITS-2, clarified its status as a single species (Manguin et al. 1999).

In the present study, canonical variate analysis, discriminant analysis and cluster analysis were used, based on the new variables generated by principal components analysis (PCA), to select an aggregate of morphological characters which collectively could differentiate females of five species [four species present in the South (Putumayo) and one species from Northwest Colombia] pertaining to the subgenus An. (Nyssorhynchus) with a high level of confidence.

\section{MATERIALS AND METHODS}

Collection of Anopheles - Adult mosquitoes were collected in three localities of the municipality of Puerto Asís $\left(00^{\circ} 30^{\prime} 57^{\prime \prime} \mathrm{N} ; 76^{\circ} 29^{\prime} 42^{\prime \prime} \mathrm{W}\right)$ and one locality in the municipality of Puerto Guzmán ( $00^{\circ} 58^{\prime} 13^{\prime \prime N}$; $76^{\circ} 35^{\prime} 09^{\prime \prime} \mathrm{W}$ ) in the department of Putumayo, Southern Colombia. In addition, An. nuneztovari mosquitoes were collected in the municipality of Segovia $\left(07^{\circ} 05^{\prime} 00^{\prime \prime} \mathrm{N} ; 74^{\circ} 42^{\prime} 13^{\prime \prime} \mathrm{W}\right)$, department of Antioquia, Northwest Colombia.

Series were obtained by rearing larvae collected in the field. Larvae were reared individually and the exuviae preserved in $70 \%$ alcohol prior to mounting for taxonomy. Some larvae were also preserved for taxonomy. Once the adult emerged it was identified using traditional keys (Faran 1980) and one of its hind legs and wings were cut off for morphometric measurements.

Several isofamilies were also reared from females collected on human landing catches. The females were allowed to feed on mice in the laboratory and three days later were induced to oviposit by submitting them to stress by cutting off one wing and hind leg before placing them in pots containing water. Ten eggs were removed from each oviposition vial for species identification (Lounibos et al. 1997) and larvae were permitted to eclode from the others. These insects were raised to adult stage before continuing the same procedure describing above. Genitalia of the males of each isofamily were removed and retained for species identification.

Insects for morphometric study - The morphometric study was carried out with 115 females pertaining to five species of the subgenus Nyssorhynchus. An. rangeli (20 individuals), An. oswaldoi (24 individuals) and An. triannulatus (18 individuals) from Putumayo were obtained from series. The study also employed 33 individuals of $A n$. benarrochi that had been identified based on morphology of eggs, larval and pupal exuviae of individuals from each isofamily. Twenty individuals of $A n$. nuneztovari were identified from larvae collected in the department of Antioquia and were also included in the analysis due to similarities observed between this species and An. benarrochi from Southern Colombia.

Measurements - To analyse the usefulness of the characteristics in Faran's key (1980) and those of Delgado and Rubio-Palis (1993) for taxonomic discrimination of the Nyssorhynchus species found in Southern Colombia, the following characters from legs and wings spots were measured using material fixed with transparent tape onto microscope slides: (1) the ratio of the humeral pale spot length of the costal vein to prehumeral dark spot length of the same vein, (2) subcostal pale spot length of the costal vein to subcostal dark spot of the same vein, length ratio, and (3) basal dark spot of hind tarsomere 2 to the total length of the same tarsomere. The morphological terms and abbreviations used follow Harbach and Knight $(1980,1982)$ and Wilkerson and Peyton (1990).

The following lengths of wing spots, whose measurements showed the greatest degree of precision and accuracy following the criteria of Sokal and Rohlf (1995), were selected for the multivariate analyses: (1) humeral dark, (2) presectoral pale, (3) sector pale, (4) preapical dark and (5) preapical pale. The following spots on the hind legs were selected in the same way: (1) dark of hind tarsomere 1 (Ta-III $)_{1}$, (2) pale of hind tarsomere 2, (3) dark of hind tarsomere 2, (4) pale of hind tarsomere 3 and (5) pale of hind tarsomere 4.

A Nikon model SMZ-1 stereomicroscope with magnification of 20X and a graduated micrometer with a scale divided into 100 units, each equivalent to $38 \mu \mathrm{m}$, was used for the measurements. The outlying individuals in an analysis of the Mahalanobis distances were measured again to correct possible errors of measurement or data entry.

Multivariate analysis - A principal component analysis (PCA) was carried out, with the objective of examining morphometric relations between the diverse taxa. The PCA involves a priori assumption that all the individuals belong to a single group, within which it is hoped to detect the species (Pimentel 1992). Since the first four principal components gave rise to $94 \%$ of the original variance, they were used as new variables to carry out canonical variate analysis. The objective of this analysis was to maximise variation between the species and minimise intraspecific variation. The projection of the individuals onto the first two canonical factors permitted visual examination of the ordering of the diverse taxa in the multivariate space (Pimentel 1992).

To examine the relationship of morphological similarity between the species, cluster analysis was performed based on Mahalanobis distances matrix, obtained from the first four components of a PCA. These distances were used to construct a dendrogram using the unweighted pairs group method analysis (UPGMA). This dendrogram was compared visually with the hypothetical phylogenetic tree proposed by Faran (1980).

Mahalanobis distances were used for the discriminant analysis, these being a measure of the distance of each individual from the centroid of each species. Each dis- 
tance is associated with a probability of pertaining to each species and this was used to classify the females into the most probable taxa. Such a reclassification was compared with that carried out a priori, verifying concordance between the two by means of the Kappa statistic. A concordance value of 0.81 to 0.99 is considered to be almost perfect (Landis \& Koch 1977). Data were analysed using the computer programmes NTSYS (Applied Biostatistics Inc 1998), JMP (SAS Inst 1999), STATA (Stata Corp 2000) and Excel (Microsoft 2000).

\section{RESULTS}

Characteristics used in keys - Overlap was found between the ranges of the characteristics measured and those used in conventional keys (Faran 1980, Faran \& Linthicum 1981, Delgado \& Rubio-Palis 1993, Rubio-Palis 2000) for An. oswaldoi, An. rangeli, An. benarrochi and An. nuneztovari (Table). In contrast, An. triannulatus could be distinguished from the other species principally by the dark proportion of hind tarsomere 2 and the size of the subcostal pale spot, which also presented the greatest variability.

Canonical variate analysis - The centroids of each species could be differentiated statistically in the multivariate space formed by canonic factors 1 and $2, A n$. triannulatus being the species which was best discriminated. When each female was projected onto the canonical factors 1 and 2 and the most external individuals of each species connected by straight lines to form polygons, a good interspecific discrimination continued to be evident (Fig. 1). Nevertheless there was an overlap of less than $10 \%$ between the polygons corresponding to $A n$. benarrochi and An. oswaldoi and also between $A n$. rangeli and $A n$. nuneztovari, indicating that the few individuals localized in these areas cannot be assigned with confidence to any of the species.

Cluster analysis - Based on the dendrogram, An. triannulatus showed the greatest morphological differentiation, while An. nuneztovari and An. rangeli were the most similar species (Fig. 2).

Reclassification of the females into their species - The Kappa statistic showed a degree of concordance of $89 \%$ between the classification predicted by the Mahalanobis distances and those obtained by the examination of series and isofamilies, representing an almost perfect reclassification according to the criteria of Landis and Koch (1977). An . benarrochi reclassified correctly for $91 \%, A n$. oswaldoi for $91.7 \%$, An. rangeli for $85 \%$, An. nuneztovari for $90 \%$ and An. triannulatus for $100 \%$ of specimens.

\section{DISCUSSION}

The morphometric multivariate techniques demonstrated that some combinations of morphological variables may serve to classify in their respective species approximately $90 \%$ of the females of the subgenus $A n$. (Nyssorhynchus) included in the present study, quantitatively and without ambiguities. In contrast, conventional keys do no allow a correct classification to species in the majority of the same females. Thus, canonical variate analysis showed a clear separation of the different species in the space created by the first two canonical variables, which represent the greatest portion of the significant variance $(93.087 \%)$.

The dendrogram obtained based on the Mahalanobis distances between the centroids of the species and projected onto the canonical factors (Fig. 2) presented a good correlation with the hypothetical phylogenetic tree constructed by Faran (1980) for the subgenus Nyssorhynchus (Fig. 2). An. triannulatus is the species furthest from the others in the two trees. It is noteworthy that Faran (1980)

\section{TABLE}

Mean values and ranges for the basal dark spot of hind tarsomere $2\left(\mathrm{Ta}-\mathrm{III}_{2}\right)$ to the total length of the same tarsomere; the ratio of the humeral pale spot (HP) length of the costal vein to prehumeral dark spot (PHD) length of the same vein (HP/PHD); subcostal pale spot (SCP) length of the costal vein to subcostal dark spot of the same vein (SCD), length ratio (SCP/SCD), compared with ranges reported by Faran, 1980 (1) and Delgado and Rubio-Palis (1993)

\begin{tabular}{lcccccc}
\hline Species & Trait & Mean & SD & Range & \multicolumn{2}{c}{ Ranges reported in literature } \\
& & & & & 1 & 2 \\
\hline Anopheles nuneztovari & $\mathrm{TaIII}_{2}$ & 0.30 & 0.02 & $0.25-0.35$ & $0.20-0.32$ & $0.11-0.44$ \\
$\mathrm{~N}=20$ & $\mathrm{HP} / \mathrm{PHD}$ & 1.74 & 0.43 & $1.20-2.30$ & $0.70-1.70$ & $06.0-4.50$ \\
& $\mathrm{SCP} / \mathrm{SCD}$ & 0.50 & 0.09 & $0.36-0.71$ & $0.20-0.55$ & $0.03-0.73$ \\
& $\mathrm{TaIII}_{2}$ & 0.25 & 0.03 & $0.20-0.33$ & $0.24-0.35$ & $0.14-0.38$ \\
Anopheles rangeli & $\mathrm{HP} / \mathrm{PHD}$ & 3.30 & 1.18 & $1.40-5.00$ & $1.00-3.70$ & $1.80-4.50$ \\
$\mathrm{~N}=20$ & $\mathrm{SCP} / \mathrm{SCD}$ & 0.77 & 0.18 & $0.54-1.20$ & $0.45-1.00$ & $0.53-0.80$ \\
& $\mathrm{TaIII}$ & 0.26 & 0.03 & $0.17-0.33$ & $0.36-0.55$ & $\mathrm{ND}$ \\
Anopheles benarrochi & $\mathrm{HP} / \mathrm{PHD}$ & 2.27 & 0.55 & $1.70-3.30$ & $>2.5$ & $\mathrm{ND}$ \\
$\mathrm{N}=33$ & $\mathrm{SCP} / \mathrm{SCD}$ & 0.32 & 0.09 & $0.10-0.55$ & $0.30-0.50$ & $\mathrm{ND}$ \\
& $\mathrm{TaIII}$ & 0.16 & 0.03 & $0.10-0.25$ & $0.12-0.25$ & $0.11-0.22$ \\
Anopheles oswaldoi & $\mathrm{HP} / \mathrm{PHD}$ & 2.51 & 0.56 & $1.60-4.00$ & $1.60-3.00$ & $1.00-3.50$ \\
$\mathrm{~N}=24$ & $\mathrm{SCP} / \mathrm{SCD}$ & 0.20 & 0.14 & $0.04-0.66$ & $0.10-0.50$ & $0.11-0.44$ \\
& $\mathrm{TaIII}$ & 0.37 & 0.07 & $0.26-0.54$ & $0.40-0.70$ & $0.20-0.43$ \\
Anopheles triannulatus & $\mathrm{HP} / \mathrm{PHD}$ & 1.35 & 0.46 & $0.60-2.30$ & $0.50-1.30$ & $0.40-1.10$ \\
$\mathrm{~N}=18$ & $\mathrm{SCP} / \mathrm{SCD}$ & 0.14 & 0.05 & $0.04-0.25$ & $0.10-0.20$ & $0.07-0.23$ \\
& & & & &
\end{tabular}




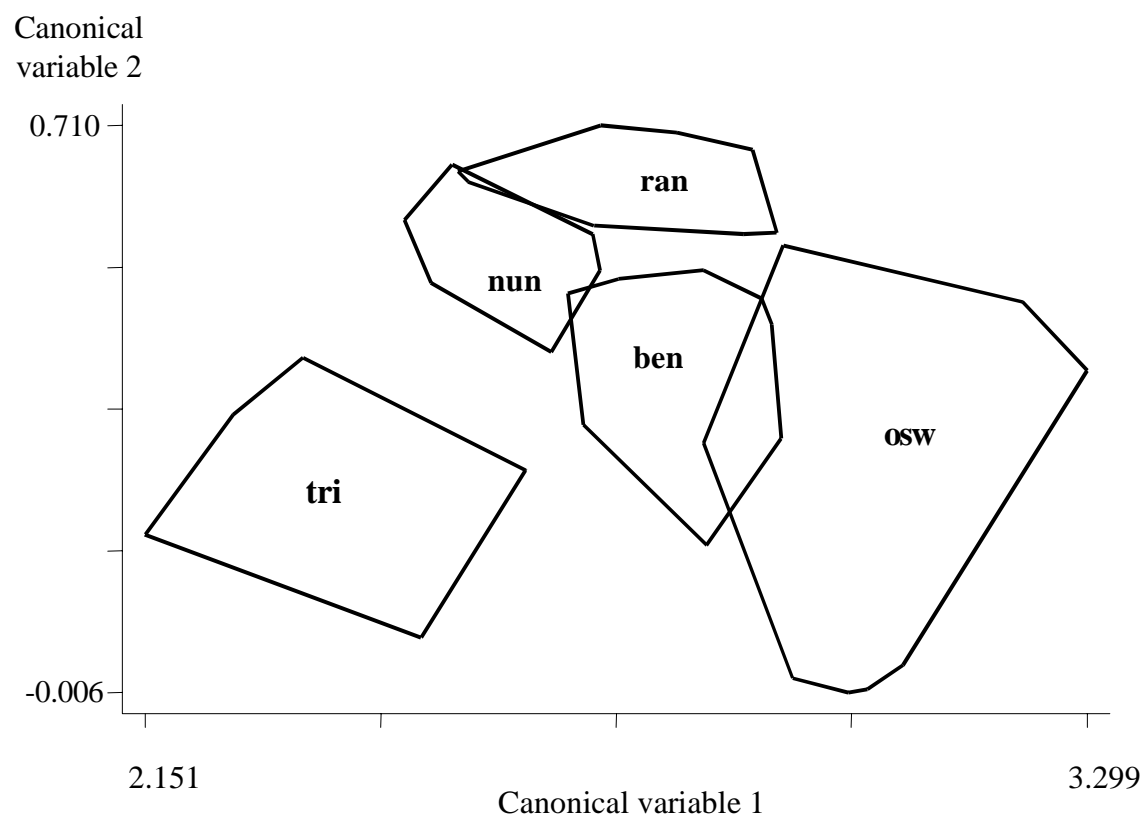

Fig. 1: polygons formed based on the projection of the individuals of each species onto the canonical variables 1 and 2, which gave rise to the greatest percentage of the total variation. ben: An. benarrochi, ran: Anopheles rangeli, nun: An. nuneztovari, tri: An. triannulatus, osw: An. oswaldoi.

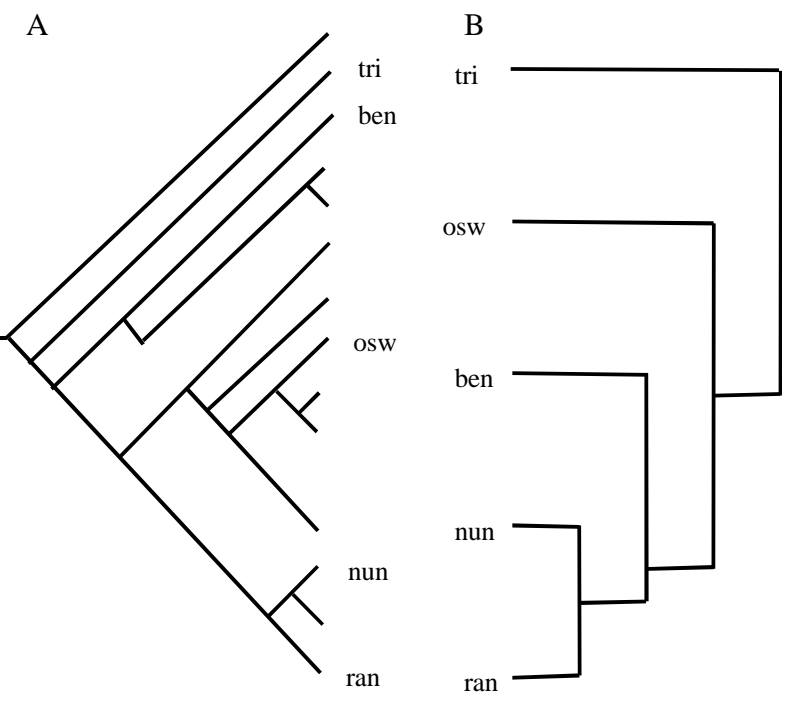

Fig. 2: comparison between the phenetic and phylogenetic relationship of five species of Anopheles. A: hypothetical phylogenetic tree proposed by Faran (1980) of the section Albimanus of the subgenus Nyssorhynchus; B: dendrogram constructed by UPGMA based on the Mahalanobis distances matrix. ben: An. benarrochi, ran: An. rangeli, nun: An. nuneztovari, osw: An. oswaldoi, tri: An. triannulatus.

removed this species from the subgroup Oswaldoi, which contains all those in the present study, placing it in the subgroup Triannulatus. An. rangeli and An. nuneztovari are located very close to each other in the dendrogram, supporting the hypothesis that they are sister groups (Faran 1980). On the other hand, An. oswaldoi and An. benarrochi present themselves as belonging to separate groups, as in the hypothetical phylogenetic tree of Faran (1980).

The only unexpected position was that of $A n$. benarrochi, which in our dendrogram occupies a position close to An. nuneztovari and An. rangeli. This is in disagreement with the hypothetical phylogenetic tree of Faran (1980), and may be due to the fact that populations from the south of Colombia represent a different morphologic variant to that studied by that author (Quiñones et al. 2001). According to Faran (1980) An. benarrochi is closely related to An. strodei, based on comparison of some structures of the male genitalia (basal lobe extending apically and rugose on the apical margin of the ventral clasper). Unfortunately we were not able to include the latter species in our study because no specimens were available. In the strict sense, comparing the hypothetical phylogenetic tree of Faran (1980) with our dendrogram only makes sense if the species evolved at a constant velocity such that the lengths of the branches on the tree represent equal evolutionary distances for each species; however our comparison only seeks to establish concordance between the phenetic similarities of the species and their phylogenetic relationships, considering that the morphological features grow in an integrated manner peculiar to each species.

The classification predicted by the discriminant functions derived from the Mahalanobis distances showed an almost perfect concordance (Kappa $=0.89)$ according to Landis and Koch (1977). This result shows the potentiality of morphometry to separate species of the series Oswaldoi, subgenus Nyssorhynchus of Anopheles in Southern Colombia, whose adult females present morphological characteristics that do not permit accurate determination using existing keys. 
In conclusion, the traditional multivariate morphometry employed during the present study demonstrated its usefulness in separating females of five species of the subgenus Nyssorhynchus from Southern and Northwest Colombia, that are difficult to identify using the dichotomous morphological keys currently available. It is important to point out that this is the first study to use multivariate techniques to resolve taxonomic problems in the subgenus Nyssorhynchus in Colombia. The evidence presented here justifies continuation of the search for groups of variables and techniques of traditional and geometric morphometry to achieve the maximum degree of discrimination among adult females of these and the other 25 species of Nyssorhynchus.

\section{ACKNOWLEDGEMENTS}

To Dr Iván Darío Vélez, Director of the Programa de Estudio y Control de Enfermedades Tropicales for his support and encouragement of the project. To the entomologists Fredy Ruiz, Guillermo Rua, Winston Rojas, Diana Sierra, Eduar Bejarano and Dora A Estrada for their collaboration during different stages of the study. To Drs William Galarza, Ignacio Palacios and Edmundo Caicedo del Departmento Administrativo de Salud from Putumayo for logistic support in field collections. To Dr Bruce Alexander for reviewing this manuscript.

\section{REFERENCES}

Añez N, Valenta DT, Cazorla D, Quicke DJ, Feliciangeli MD 1997. Multivariate analysis to discriminate species of pheblotomine sand flies (Diptera: Psychodidae): Lutzomyia towsendi, L. spinicrassa and L. youngi. J Med Entomol 34: 312-316.

Applied Biostatistics Inc 1998. NTSYSpc version $2.02 \mathrm{~h}$. Website: http://www.Exetersoftware.com

Delgado N, Rubio-Palis Y 1993. Identification of Anopheles (Nyssorhynchus) (Diptera: Culicidae) occurring in Western Venezuela. Mosq Syst 25: 222-230.

Faran ME 1980. Mosquitoes studies (Diptera: Culicidae) XXXLV. A revision of the Albimanus section of the subgenus Nyssorhynchus of Anopheles. Contrib Am Entomol Inst 155: 1-125.

Faran ME, Linthicum KJ 1981. A handbook of the Amazonian species of Anopheles (Nyssorhynchus) (Diptera: Culicidae). Mosq Syst 13: 1-18.

Gebre-Michael T, Medhin G 1997. Morphometric separation of female of Phlebotomus (Phlebotomus) dudoscqui and $P$. (P.) bergeroti (Diptera: Psycodidae). J Med Entomol 34: 383-386.

Harbach RE, Knight KL 1980. Taxonomists Glossary of Mosquito Anatomy, Plexus Publishing, Marlton, NJ.

Harbach RE, Knigh KL 1982. Corrections and additions to taxonomists glossary of mosquito anatomy. Mosq Syst 13: 201-217.

Landis JR, Koch GG 1977. The measurement of observer agreement for categorical data. Biometrics 33: 159-174.

Lounibos LP, Duzak D, Linley JR 1997. Comparative egg morphology of six species of the Albimanus section of Anopheles (Nyssorhynchus) (Diptera: Culicidae). J Med Entomol 34: 136-155.

Manguin S, Wilkerson RC, Conn JE, Rubio-Palis Y, DanoffBurg JA, Roberts DR 1999. Population structure of the primary malaria vector in South America, Anopheles darlingi, using isozyme, random amplified polymorphic DNA, internal transcribed spacer 2, and morphologic markers. Am J Trop Med Hyg 60: 364-376.

Microsoft Corp 2000. Microsoft® Excel 2000, USA.

Perez L, Suarez M, Murcia L, de la Hoz F, Olano VA, Brochero H 1999. La malaria en el Amazonas conocimientos, prácticas, prevalencia de parasitemia y evaluación entomológica en mayo de 1997. Biomédica 19: 93-102.

Petrarca V, Sabatelli G, Toure YT, Dideco MA 1998. Morphometric multivariate analysis in Anopheles gambiae s.s. (Diptera: Culicidae). J Med Entomol 35: 16-25.

Pimentel RA 1992. An introduction to ordination, principal components analysis and discriminant analysis. In JT Sorensen, R Foottit (eds), Ordination in the Study of Morphology, Evolution and Systematics of Insects, Elsevier Science Publisher, Amsterdam, p. 11-28.

Quiñones ML, Harbach RE, Calle DA, Ruiz F, Erazo HF, Linton YM 2001. Variante morfológica de hembras de Anopheles benarrochi (Diptera: Culicidae) en Putumayo, Colombia. Biomédica 21: 351-9.

Quiñones ML, Linton YM, Harbach RE, Estrada DA, Erazo HF, Calle DA, Ruiz JF 2000. Malaria vector species in Southern Colombia: species determination and natural infectivity. XVth Int Congress Trop Med Malaria, Cartagena, Abstracts, p. 108.

Quiñones ML, Suarez MF, Fleming GA 1987. Distribución y bionomía de los anophelinos en la Costa Pacífica de Colombia. Colombia Med 16: 19-24.

Quiñones ML, Villarreal LI, Suarez MF 1992. Distribution and biting behaviour of Anopheles species in Casanare, Colombia. Symposium summaries. In GL Clark, MF Suarez (eds), Mosquito Vector Control and Biology in Latin America. A Second Symposium. J Am Mosq Control Assoc 8: 305-306.

Rubio-Palis Y, Manguin S, Ayesta C, Guzman H, Arcia JM, Gonzalez J Jr, Perez E 1997. Revisión taxonómica de los anofelinos vectores de malaria en el sur de Venezuela. Bol Dir Malariol San Amb 37: 35-48.

Rubio-Palis Y 1998. Caracterización morfométrica de poblaciones de Anopheles (Nyssorhynchus) darlingi del sur de Venezuela. Bol Entomol Venez 13: 141-172.

Rubio-Palis Y 2000. Anopheles (Nyssorhynchus) de Venezuela: Taxonomía, Bionomía, Ecología e Importancia Medica. Escuela Malariol San Amb, Maracay, Venezuela. 120 pp.

SAS Institute Inc 1999. JMP version 3.2.6. SAS Institute Inc. Website: http://www.JMPdiscovery.com.

Sokal RR, Rohlf FJ 1995. Biometry: the Principles and Practice of Statistics in Biological Research, 3rd ed., WH Freeman and Company, New York.

Stata Corp 2000. Intercooled STATA 6.0 for Windows 98/95/ NT. University Drive East, College Station, Texas, USA. Website: http://www.stata.com.

Suárez MF, Quiñones ML, Wirtz RA 1990. Anopheles rangeli a suspected vector of Plasmodium vivax in Southern Colombia. 39 Annu Meeting Am Soc Trop Med Hyg, New Orleans, Abstracts, p. 158.

Villegas ME, Quintero R, Manotas EL 2000. Malaria en el Guainía, 1998; frecuencia y aspectos entomológicos. Rev Col Entomol 26: 46-9.

Wilkerson RC, Peyton EL 1990. Standardized nomenclature for the coastal wing spots of the genus Anopheles and other spotted-wing mosquitoes (Diptera: Culicidae). J Med Ent 27: 207-224. 